\title{
Knowledge Management and Action Learning in Blended Training Activities
}

\author{
Pattama Chandavimol, Onjaree Natakuatoong, Pornsook Tantrarungroj \\ Faculty of Education, Chulalongkorn University, Bangkok, Thailand \\ Email: pattama.chandavimol@gmail.com
}

Received July 2013

\begin{abstract}
The purpose of this study is to propose blended training activities by applying the knowledge management techniques and action learning into the training process. The proposed data are from study of the theory, documents, surveys, problems, and needs in knowledge Management and Action Learning to develop blended training techniques. The questionnaires were answered by 261 respondents who are personnel development staffs experienced in designing training courses, organizing these courses, and writing up training projects for government units in Thailand. The process development was brought to discussion with 5 field experts in distance learning, training, instructional design and curriculum development, Educational Technology and Communication, and organization development areas. The data were analyzed by using basic statistical techniques such as frequency distribution, percentage, descriptive and open-ended surveys, brought to analyze and categorize the information, then propose the findings. The key findings show that organizing the blended training process consists of 3 steps: pre-training, training, end-of-training. In each step, the blended activities, traditional classroom training, online and E-Learning are used with knowledge management activities and action learning. Then using technology to enhance learning processes such as blogging, chat, discussion boards, e-mail, E-learning courseware, and learning management systems.
\end{abstract}

Keywords: Action Learning; Blended Training; Knowledge Management

\section{Introduction}

Training is regarded as an important element in today's organization management because it enhances the efficiency and capability of the organization. Therefore, in a training context, personnel development staff needs to be able to explain the concepts, approach and process of the training, as well as to develop and improve the training process. Each training program requires certain time and budget allocations; therefore, there is an expectation that such training should give proper return on those investments and can make the changes that organization is aiming to.

Successful training depends on the readiness and support of the organization, training service provider, trainer, trainees in all processes as described below. (Sukmuang \& Ek-un, 2009).

- Pre-Training Support. The period that prepares the readiness of the personnel, organizer, and the trainees. The needs of the training program, the desired capability after the training are addressed. The meeting between trainer and trainees can be organized during this stage.

- Training Support. Sufficient and proper supports during the training should be provided including tools, equipments, materials as well as other facilitations.

- End-of-training Support. This can be in the form of feedback, evaluations, remarks, and surveys from the trainees, trainer, and training organizer.

The training program approach and content need to be changed as the effect from the economic uncertainty in Thailand. (Thieanphut, 2000). This statement is endorsed by Boonyatarokul (2002) who opined that the training methods should include changing both the methods and the contents of the training. Especially the employees in the organization in the current situation will learn less and slower if the training approach remains the same. (Natakuatoong, 1997). Kusumawalee (1997) holds a similar view. He believes that the in-class training with a teacher-centric approach is not enough. The organization needs to develop an environment in which the employees can have continuous learning and stimulate the learner-centric approach, which will lead to the learner applying the new knowledge in other innovative ways, which is very important.

The information technology digital world has brought in various new technologies to play a significant role in not only people's lives but also in the training mechanisms. E-learning, web-board class discussion, email, and learning management systems have become a platform to help people learn. These new electronic tools can be used to improve the training process. The classroom-based learning and E-Learning have their own benefits. In designing a training or education curriculum, the instructional designer should bring in both methods to complement each other and fill in the deficiencies that each has on its own, forming a blended learning approach. Finding a perfect combination of the two methods depends on the characteristics of the specific training contents, which may be different, and requires skills on the part of the instructional designer. To give the maximum benefits to the trainees, according to Swart (2005), an effective training design needs to correlate with the learning objective, and can be developed by various training to meet the organization's objectives.

Bonk, Graham, Cross, \& Moore (2006) concluded that blended learning is the most efficient method for learning, by blend- 
ing the classroom-based learning and e-Learning. These systems are designed to solve a variety of teaching-learning problems. Miner \& Hofmann (2009) describe blended learning as not only combining the delivery, but also consisting of the infrastructure and method of teaching the content. The blended learning focuses on flexibility by applying both the face-to-face and online learning to address to the different needs of the trainees. This is to ensure each trainee can achieve his/her learning objectives.

In the era of education evolution and knowledge-based society, learning in the 21 st century has changed. $30 \%$ of the new knowledge is the learning from training, whereas $70 \%$ is from work and experience exchange. The US's Labor Department has estimated that more than $70 \%$ of knowledge is incurred from experience and $30 \%$ from the training and education. Since knowledge is internal and is difficult to communicate with others in a useful and efficient manner, tools are needed to convey such knowledge for the organization's ultimate benefit.

This so-called tacit knowledge held by people will be processed by the knowledge management system, starting with identifying, searching, planning to acquire, developing and bringing out the knowledge from people. Then, the knowledge will be stored and classified. The valued knowledge will be recorded in a database, transferred and disseminated in fast and appropriate manner across the organization; with the intention that knowledge can be used in making decisions, solving problems, improving the organization and increasing the new knowledge of the organization. This cycle of learning will feed back into itself, repeating the process indefinitely.

The tacit knowledge that was processed by knowledge management system can be used as a source in learning and developing the skills. Knowledge should be always stored in knowledge repository which can be accessed easily by all employees in the organization by using modern technologies and innovations to maximize access to such knowledge (Candlin \& Wright, 1992). This is the advantage of deploying knowledge base to the continual training. The trainees can have access to the experts rapidly and the knowledge from the source is generated by and transferred from skillful employees in the organization to others. This creates the knowledge development value chain and enhances each employee's own knowledge. The employees will acquire this learning with practice.

Marquardt (1999) looks at action learning for building knowledge management systems through 4 perspectives: 1) the source of knowledge. In action learning, the learners should think about the organization's resources, facilities in sharing the knowledge and how to develop knowledge, 2) the knowledge development. Learners should search and develop new methods in solving problems because the old knowledge may obsolete, 3) the knowledge storage. The organization should classify which knowledge should be stored, provide an encoding system, and protect that knowledge and 4) the knowledge transfer and utilization. During the reflection and feedback period, the knowledge becomes clearer and meaningful. Group members gain knowledge in different fields and develop their talents to become experts in those fields. They will then transfer the knowledge, wisdom and experience derived from group problemsolving to the communities that they belong to.

Action learning is developed from experience and knowledge, as well as individual and group skills. Groups use action learning to understand the difficult problems in the organiza- tion's work.

Echols (2010) states that the next issue that needs to be addressed is how to integrate the key elements in action learning with practice learning. The $30 \%$ of learning that utilizes traditional teaching methods (i.e. formal learning) needs to be made as easy to use and flexible as action learning (informal learning). Formal learning is not led by the learners, so its contents, learning methods, and objectives need to be selected by experts, because experts have the highest competencies in these areas. Action learning, on the other hand, draws on the collective knowledge and experience of the learners, and requires good access to online knowledge resources so that they can effectively share their knowledge and experience. Because these two methods (formal and informal) are fundamentally different, integrating them in a way that will allow them to complement each other is one of the biggest challenges.

In designing the training, the practices need to follow the changes in the organization. The personnel development staffs must know how to meet those changes (Richey, Fields, \& Foxon, 2001). To create a successful blended learning, the personnel development staffs should think about the training objectives previously set, the duration of learning, and the differences in learning methods of the learners as the foundation for designing the training activities. The blended teaching method on the web can create closer relations between the trainer and trainees, as they can exchange experience, and understand and respect their classmates. In addition, the trainees will receive instant feedback which facilitates each student's learning.

In organizing useful training for the trainees, the personnel development staffs must possess the training design capability as a significant foundation. The researcher, being in the position of an educational technology expert, is playing a significant role in bringing technologies together to promote the learning, and the learning methods, and therefore is proposing the knowledge management and learning from blended training to improve the training design capability. The researcher proposes to bring the blended training process, knowledge management process, and action learning process together to blend with training activities.

\section{Research Methodology}

There are four phases of this study. Phase 1 is to study the papers, research and literature under the context of blended training, knowledge management, action learning and competency in training design. Phase 2 is to explore the situation, problems, and needs of personnel development staff in regards to the design of blended training, by applying the knowledge management and action learning principles. Phase 3 is to design the blended training programs with the knowledge management principles and action learning to improve the training program design competency. Finally, phase 4 is to study the opinions of five field experts in distance learning, training, instructional design and curriculum development, Educational Technology and Communication, and organization development areas on the blended training process.

\section{Population and Sample Size}

The population in this research is the personnel development staff in government units, responsible for training design, management and project development. The population will be 
limited to those having more than two years of experience in a training job in these government units.

\section{Instruments and Data Analyses}

The researcher has developed a questionnaire as a survey tool. The tool development process is as follows:

- Study the papers, research and literature under the context of blended training, knowledge management, action learning and competency in training design, and apply them as a framework for tool development.

- Study and synthesize the contents of blended training by applying the questionnaires used to survey knowledge management and action learning principles, and put together the checklist and open-ended questions regarding the past theory and research.

- The researcher analyzed the data to explain the situation and problems of the blended training programs by using the knowledge management and action learning principles.

After the data has been analyzed, the designed training process is brought to discussion with 5 field experts in distance learning, training, instructional design and curriculum development, Educational Technology and Communication, and organization development areas.

\section{Findings}

The key findings related activities and technology in blended training from the sampling government unit group follow: 93.9\% of the staff have access to learning technology, $91.2 \%$ have experience in action learning, 90.4\% have a knowledge management plan, and $89.3 \%$ have a training program which is designed to use flexible and blended training.

The most popular technology that their organizations have provided to access to training programs are e-mail at $25.6 \%$, followed by web boards at $19.8 \%$, and Web Portals at $14.5 \%$. The technologies that the sampling group has provided in low level were Web Blog or Blog at $10.0 \%$, Chat at $7.6 \%$ and Discussion Board at $7.3 \%$.

The extra activities that can increase work-related knowledge the most were asking the advice of an expert at $13.5 \%$, then action learning at $13.2 \%$, training and practice at $12.3 \%$, and self-directed learning from readings at $11.3 \%$. The finding indicates that learning methods using television-based education, added readings, homework and exercises is inadequate, with only $1.3 \%$ rating them as the most effective methods.

The technologies that were regarded as tools for learning were Internet 27\%, e-Learning 22.2\% and Data Warehouse $12.9 \%$.

The most convenient tool for employees in the organization to search for knowledge was a knowledge-based platform, including the organization's database on the Internet or the company's Intranet, at $49.1 \%$.

The activities that promoted the employees' learning level were practical workshops at $17.3 \%$, panel discussions at $15.3 \%$ and small group meetings at $14.5 \%$.

The most frequently organized activity to develop knowledge was the knowledge sharing activity, including close work collaboration at $23.5 \%$; followed by action learning at $22.5 \%$, the blend of group and individual knowledge, which later became the new knowledge, at $13.1 \%$.

$28.9 \%$ of trainees reported that the most formatted knowledge could be found in the operational processes and flow charts. $25.8 \%$ reported Intranet linking to the knowledge in forms of documents, and $16.9 \%$ reported knowledge portal.

According to the respondents, the most useful way to share the knowledge earned from knowledge management activities was mostly in the form of operational manuals at $26.7 \%$, knowledge-sharing corner at $16.6 \%$ and storing the knowledge in the organization's database at $14.3 \%$.

The most effective way to understand the problems was reported as posting the questions at $30.2 \%$, expressing the opinions generated by past experience at $26.8 \%$ and group discussion at $25.6 \%$.

The most effective way to address problems to improve the job was helping to suggest the problem solutions among the group at $32.1 \%$, learning from each other and selecting the most practical solutions at $26.8 \%$, discussing in a group and planning to bring solutions to practice at $20.7 \%$.

The most outstanding behavior found to create reflective knowledge was group members bringing in and sharing their past experience at $52.3 \%$.

From these findings, the researcher proposed Technology enhanced in Blended Training Activities in "Table 1", and the knowledge management and action learning in blended learning activities in "Table 2".

\section{Discussion}

Blended training is suitable for some training courses. The trainees need to allocate some time to the training and have a high level of responsibility.

In identifying problems, the desired knowledge, and practitioner group, the planner needs to analyze the problems and set up the framework in selecting problems to retrieve the most useful knowledge.

There should be many blended training activity pilot projects to lead to the activity development to meet the objectives of each training course.

\section{Acknowledgements}

Financial assistance was provided by the 90th anniversary of chulalongkorn university fund (Ratchadaphiseksomphot Endowment Fund).

Table 1.

Technology enhanced knowledge management and action learning in blended training activities.

\begin{tabular}{ll}
\hline Group of Technology & Tools \\
\hline Communication & Internet \\
Technology & Intranet \\
& e-mail \\
& Learning management systems \\
& Chat rooms \\
Collaboration Technology & Web boards \\
& Web blog \\
& Discussion boards \\
& Data warehouses \\
& Document management systems \\
Storage Technology & Knowledge repositories \\
& e-Learning courseware \\
& e-books \\
& Video Clips \\
Learning Technology & Experts yellow pages \\
& Knowledge maps \\
& Internet search engines \\
\hline
\end{tabular}


Table 2.

Knowledge management and action learning in blended training activities.

\begin{tabular}{l} 
Steps $\quad$ Activities and Method \\
\hline
\end{tabular}

Pre-Training

Trainee Orientation

1. The organizer prepares the

trainees.

(Face to Face)

Training

2. The trainees identify problems and desired knowledge, set up communities of practice (CoPs). (Face to Face and online)

3. Trainees share the training, information, experience and opinions. (Face to Face and online)

4. The trainees acquire new knowledge (Online)

5. The trainees attend the training in their knowledge development groups by sharing the learning and create the solutions to solve problems (Online)

6. The trainees apply the knowledge to their work (Action Learning and online)

\section{The trainees store} own and group knowledge into the system and utilize the information. (Online)
1.1 The organizer informs the trainees of the training objectives, activities, process, and evaluation criteria. 1.2 Guest lecturer shares the knowledge and the importance of involving the new technology into training. 1.3 The organizer demonstrates and gives hands-on practice by using communication and collaboration technologies such as logging in to the relevant web sites, online chat, individual and group web blogs, self-introduction, web board, announcements, and file-upload.

1.4 Guest lecturer shares the information about knowledge management and action learning.

1.5 The trainees complete an evaluation form of their capability in training design.

1.6 Each trainee submits his/her own current project to the organizer.
2.1 Each trainee proposes the problems found and describes their work problems to gain a variety of information, from face-to-face and online chat channel.

2.2 The trainees summarize and record the problems found at work into their blog.

2.3 The trainees divide the community of practice into 5-person groups, using work position and role. Each group has group leader, leader assistant, secretary, and facilitator.

2.4 The trainees in the community of practice help each other to assess the problems found at work, and then propose solutions via chat board, and record this information in a group blog.

3.1 The trainees in the community of practice explain the significance and source of the group's problems and obstacles. 3.2 The trainees in the community of practice propose the current situation, brainstorm to select the problems that they thought were the most important and need rapid remand to improve work efficiency.

3.3 The trainees in the community of practice pose questions about the problem criteria.

3.4 The trainees in the community of practice propose solutions to solve the problems, reflecting on the opinions gathered from exchanging information via chat and web board.

3.5 The trainees in the community of practice help to document the process, by summarizing the problems, the significance, and source of the problems, and the solutions used to solve the problems in the group blog.

4.1 The trainees access to E-Learning

- e-Learning: training design and strategy

- $\quad$ e-Book: learning psychology of adults, analysis of the training needs.

- Summarize the learning in their own blogs

4.2 Each trainee acquires more information on training and media development design from the Internet, and other knowledge sources provided. Then record the learning in their own blog.

4.3 The facilitator brings together the knowledge from group's web board, records it, and uploads it to the facilitator's own blog, and to group blog.

4.4 The trainees in the practitioner society discuss, bring their questions, discuss the information that the facilitator brought together, propose, brainstorm solutions to solve the problems via chat board, and finally record their findings in the group blog.

4.5 The trainees meet the online experts in the blended training design via online chat.

4.6 The facilitator leads the community of practice to summarize the solutions, and documents the solutions, and records them in group blog.

5.1 The facilitator and leader of the community of practice of each group share the knowledge, and discuss plans to select the potential problems. The group writes up the training project via group chat board and record in the group blog. 5.2 The online expert suggests the guidelines for training projects via chat board and online chat.

5.3 The trainees in the community of practice help improve the project and record in group blog.

5.4 The organizer summarizes the activity results, including:

- The submission of assignments before the deadline

- The time of attending online courses

- The time of recording knowledge in personal and group blogs

- The frequency in expressing the opinions and online debate

5.5 Group leader in each community of practice report the project progress via email and group blog. The trainees in each community of practice introduce other groups via their group blogs.

5.6 The trainees in the community of practice help make improvements based on the suggestions from other groups and update the information on their group blogs.

6.1 The trainees apply the group project to test on their real work.

6.2 The trainees record the information found from the trial into their own blog.

6.3 The facilitator of each community of practice leads the exchanges of opinions, evaluations, and suggestions after the trial, and then summarizes the findings on group blog.

7.1 The organizer suggests the method to manage, store, and utilize the documents in e-book online format.

7.2 The trainees store their own and community of practice knowledge into the system in the form of knowledge maps on the web site.

7.3 The trainees utilize the knowledge on the web sites for further study.

7.4 The trainees record the new knowledge from personal and community of practice into their blog, dividing it into 3 categories:

- Knowledge from training

- Knowledge from sharing information

- Knowledge from eLearning 
End of training

8.1 The trainees in each community of practice propose the group project and give scores to their own group and the other groups. Other judges give scores.

8.2 The organizer summarizes the project, and makes comparisons of before and after the training.

8.3 The organizer summarizes the activities.

- The assignments that were submitted before their deadline

- The time in attending the online classes

8. The trainees in the community of practice propose the project.

- The time in recording the knowledge into personal and group blogs.

- The frequency of expressing opinions and online debate.

8.4 The management presents the certificates to the trainees and gives the awards to outstanding community of practice members.

8.5 Each community of practice brings the proposal which is amended along with the suggestions by the experts and stores it into the system.

8.6 The facilitator of each group invites the group members and leader to view their blog and projects from the training. 8.7 The trainees complete the capability survey in training design after the blended training.

8.8 The trainees complete a survey about the blended training method by using the knowledge management and action learning approaches.

\section{REFERENCES}

Echols, M. E. (2010). An informal debate: Bridging the gap between formal and informal learning. Chief Learning Officer. https://humancapitalmedia.site-ym.com/store/view_product.asp?id=1 095537\&hhSearchTerms $=$ August + and +2010

Bonk, C. J., Graham, C. R., Cross, J., \& Moore, M. G. (2006). The handbook of blended learning: Global perspectives, local designs. Pfeiffer.

Boonyatarokul, W. (2002). Lecture's manual and training manager. Bangkok: Dansutha Printing.

Candlin, D., \& Wright, S. (1992). Managing the introduction of expert systems. International Journal of Operations \& Production Management, 12, 46-59. http://dx.doi.org/10.1108/EUM0000000001295

Kusumawalee, S. (1997). Developing the learning organization guidelines in developing organization resources to develop Thailand in next century. Documents used at academic seminar in the occasion of the 80th Anniversary of the Establishment of National Institute of Development Administration.

Marquardt, M. J. (1999). Action learning in action: Transforming pro- blems and people for world-class organizational learning. Palo Alto, Calif: Davies-Black.

Miner, N., \& Hofmann, J. (2009). More than a merge: Successful blended learning demands thinking ahead and building a thorough understanding of modalities. $T \& D$. January, 30 .

NaTakuatoong, O. (1997). 2708652 Course Materials for Educational Technology in Training. Bangkok: Faculty of Education, Chulalongkorn University.

Richey, R. C., Fields, D. C., \& Foxon, M. (2001). Instructional design competencies: The standards (3rd ed.). Syracuse, NY: Eric Clearinghouse on Information Technology.

Sukmuang, U., \& Ek-un, N. (2009). Training approach according to ISO 10015 standard. Journal of Science Department Service, 57, 1417. http://lib3.dss.go.th/fulltext/dss_j/2552_57_179_P14_17.pdf

Swart, J. (2005). Human resource development: Strategy and tactics. Oxford: Elsevier/Butterworth-Heinemann.

Thieanphut, D. (2000). The HRD planning for next millennium for professional trainer. Bangkok: DNT Consultants. 